\title{
Effect of Welding Processes on Fatigue Crack Growth Behaviour of AISI 409M Ferritic Stainless Steel Joints using ASS Fillers
}

\author{
A.K. Lakshminarayanan, K. Shanmugam, V. Balasubramanian* \\ Centre for Materials Joining \& Research (CEMAJOR), Department of Manufacturing Engineering, \\ Annamalai University, Annamalai Nagar - 608 002, Tamil Nadu, India. \\ "Corresponding Author, Tel:+91-09245079322, Fax: +91-4144-238080/238275 \\ E-mail:visvabalu@yahoo.com
}

\begin{abstract}
The present investigation aims to study the effect of welding processes such as shielded metal arc welding (SMAW), gas metal arc welding (GMAW) and gas tungsten arc welding (GTAW) on fatigue crack growth behaviour of the ferritic stainless steel (FSS) conforming to AISI 409M grade. Rolled plates of $4 \mathrm{~mm}$ thickness were used as the base material and AISI $308 \mathrm{~L}$ grade austenitic stainless steel (ASS) was used as filler metal, for preparing single pass butt welded joints. Centre cracked tensile (CCT) specimens were used to evaluate the fatigue crack growth behaviour. From this investigation, GTAW joints showed superior fatigue crack growth resistance compared with SMAW and GMAW joints. The reasons for the superior performance were discussed in detail.
\end{abstract}

Keywords: ferritic stainless steel; shielded metal arc welding; gas metal arc welding; gas tungsten arc welding; impact and fatigue properties.

\section{INTRODUCTION}

There is a growing interest in the use of ferritic stainless steels (FSS), for such application in chemical processing equipment, furnace parts, heat exchangers, oil burner parts, petroleum refining equipment, protection tubes, recuperates, storage vessels, electrical appliances, solar water heaters and household appliances 1. However, Welding of FSS is faced with the problem of grain coarsening in the weld zone and heat affected zone of fusion welds and consequent low toughness and ductility due to the absence of phase 
transformation during which grain refinement can occur 2. Enormous research work has been carried out on welding of austenitic stainless steel (ASS), but the published information on welding of FSS is very limited. Villafuerte and Kerr 3 attempted to weld ferritic stainless steel by gas tungsten arc welding (GTAW) process and observed that approximately for constant values of heat input per unit distance, the equiaxed fraction increased with welding speed, as long as sufficient titanium and aluminum were present to form nucleate for the second phase. In a later study by Villafuerte et al. 4, the tin quenching of GTA welds of commercial ferritic stainless steels had shown direct evidence of heterogeneous nucleation of equiaxed grains on tin particles ahead of advancing columnar interfaces. However, the addition of titanium alone did not lead to the formation of equiaxed grains, despite an increased tendency for branching and the protrusion of some primary dendrite stalks ahead of others.

Mohandas et al., 5 made a comparative evaluation of gas tungsten and shielded metal arc (SMA) welds of AISI 430 ferritic stainless steel and found that the greater ductility and strength of GTA as compared to those of SMA welds can be attributed to the equi-axed morphology of the fusion-zone grains in the GTA welds, and also to inert gas shielding. Meyers and Toit 6 investigated the impact properties of $11-12 \%$ chromium steels and found that carbon and nitrogen affect the impact properties of the heat-affected zone (HAZ) in these steels. Silva et al, 7 investigated the microstructural characteristics of the HAZ in AISI 444 ferritic stainless steel and reported that needle-like Laves phase precipitation occurred in the $1 \Lambda \mathrm{Z}$, near the partiallymelted zone and other secondary phases such as chi and sigma were also observed, as well as nitride, carbide and carbonitride precipitates.

Most of the reported literature 3-7 focused on effect of welding processes on fusion zone microstructure, tensile and impact properties. But the published information on fatigue crack growth behaviour of ferritic stainless steel is very scant 8 . Hence, the present investigation was carried out to understand the effect of welding processes such as shielded metal arc welding, gas metal arc welding and gas tungsten arc welding on fatigue properties of ferritic stainless steel joints.

\section{EXPERIMENTAL WORK}

The rolled plates of $4 \mathrm{~mm}$ thickness AISI 409M grade FSS were cut into the required dimension (300 $\mathrm{x}$ $150 \mathrm{~mm}$ ) by plasma cutting and grinding. The initial joint configuration was obtained by securing the plates in position using tack welding. Square butt joints were fabricated using SMAW, GMAW and GTAW processes. All necessary care was taken to avoid joint distortion and the joints were made with applying clamping devices. AISI 308L ASS consumables were used to fabricate the joints. The welding conditions and process parameters used to fabricate the joints are given in Table 1. 
Table 1

Welding conditions and process parameters

\begin{tabular}{cccc}
\hline & \multicolumn{3}{c}{ Process } \\
\cline { 2 - 4 } Parameters & SMAW & GTAW & GMAW \\
\hline Welding machine & Lincoln, USA & Lincoln, USA & Lincoln, USA \\
Polarity & DCRP & AC & DCRP \\
Arc voltage (volts) & 25 & 22 & 30 \\
Welding current (amps) & 120 & 90 & 150 \\
Welding speed (mm/sec) & 3 & 2.5 & 4 \\
Heat input (J/mm) & 1000 & 800 & 1125 \\
Electrode diameter (mm) & 4.0 & 2.0 & 1.6 \\
Shielding gas & -- & Argon $(99.99 \%)$ & Argon $(99.99 \%)$ \\
Shielding gas flow rate (lt/min) & -- & 14 & 14 \\
\hline
\end{tabular}

The soundness of welded joints was checked using ultrasonic testing. The chemical composition of the base metal and weld metals was obtained using a vacuum spectrometer (ARL-Model: 3460). Sparks were ignited at various locations of the samples and their spectrum was analysed for the estimation of alloying elements. The chemical composition of the base metal and weld metals in weight percent are presented in Table 2.

Table 2

Chemical composition of base metal and weld metals

\begin{tabular}{cccccccccccc}
\hline Material & $\mathbf{C}$ & $\mathrm{Mn}$ & $\mathbf{P}$ & $\mathrm{S}$ & $\mathrm{Si}$ & $\mathrm{Cr}$ & $\mathrm{Ni}$ & $\mathrm{Ti}$ & $\mathrm{Mo}$ & $\mathbf{C u}$ & $\mathrm{Fe}$ \\
\hline $\begin{array}{c}\text { Base Metal } \\
\text { (AISI 409M) }\end{array}$ & 0.028 & 1.10 & 0.03 & 0.010 & 0.40 & 10.9 & 0.39 & 0.004 & - & - & $\mathrm{Bal}$ \\
$\begin{array}{c}\text { ASS (AISI } \\
\text { 308L) }\end{array}$ & 0.035 & 0.82 & 0.018 & 0.015 & 0.67 & 20.9 & 10.2 & - & 0.01 & 0.1 & $\mathrm{Bal}$ \\
\hline
\end{tabular}

The welded joints were sliced using power hacksaw and then machined to the required dimensions for preparing tensile, impact and fatigue test specimens as shown in Figure 1. Tensile test was conducted in 100 kN, electro-mechanical controlled Universal Testing Machine (Make: FIE-BLUE STAR, India; Model: UNITEK-94100). ASTM E8M-04 guidelines were followed for preparing and testing the tensile specimens. Since the plate thickness is small, subsize impact specimens were prepared. Impact test was conducted at room temperature using pendulum type impact testing machine (Make: ENKAY, India) with a maximum capacity of $30 \mathrm{~J}$. ASTM E23-04 specifications were used for preparing and testing the specimens. 


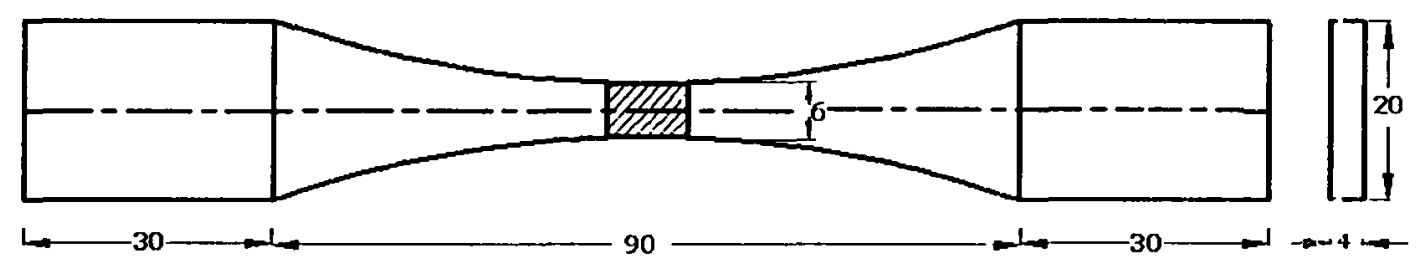

(a) Tensile specimen

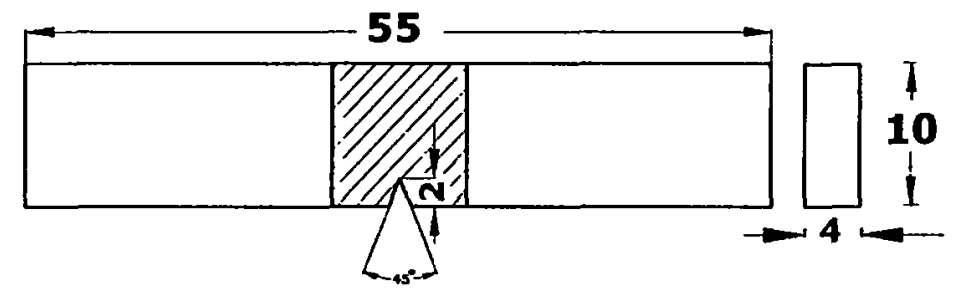

(b) Sub-size impact specimen
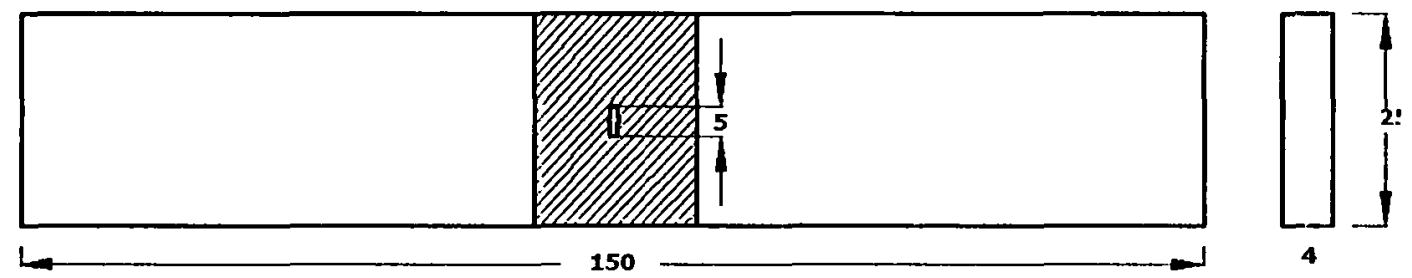

(c) Centre Cracked Tensile (CCT) Specimen

Fig. 1: Dimensions of tensile, impact and fatigue specimens. All dimensions are in ' $m m$ '

Vicker's microhardness testing machine (Make: Shimadzu, Japan and Model: HMV-2T) was employed for measuring the hardness of the weld with $0.5 \mathrm{~kg}$ load. Microstructural examination was carried out using a light optical microscope (Make: MEJI, Japan; Model: MIL-7100) incorporated with an image analyzing software (Metal vision). The specimens for metallographic examination were sectioned to the required size from the joint comprising fusion zone region and were polished using different grades of emery papers. Final polishing was done using the diamond compound ( $1 \mu \mathrm{m}$ particle size) in the disc polishing machine. The specimens were etched with $5 \mathrm{ml}$ hydrochloric acid, $1 \mathrm{~g}$ picric acid and100 ml methanol applied for 10-15 seconds.

For centre cracked tensile (CCT) specimen, the sharp notch was machined in the fusion zone region to the required length using the wire cut electric-discharge machine (EDM). Procedures prescribed by the ASTM E647-04 (ASTM, 2004) standard were followed for the preparation of the specimens. Fatigue crack growth experiment was conducted using a servo hydraulic, $100 \mathrm{kN}$ fatigue testing machine (Make: INSTRON, UK; Model: 8801). A frequency of $20 \mathrm{~Hz}$ under constant amplitude loading $(R=0)$ was used uniformly for all the specimens. Before loading, the specimen surface near the notch was polished to facilitate fatigue crack growth measurement. A traveling microscope with an accuracy of $0.01 \mathrm{~mm}$ was used to monitor the crack 
length. The specimen was loaded at a particular stress level (range), and following crack initiation from the tip of the machined notch, its subsequent propagation into the weld metal was recorded from initiation to the complete failure of the specimen. Similar crack growth experiments were conducted on a number of specimens at various stress levels, and the experimental data were recorded. The fractured surface of the fatigue tested specimens was analysed using scanning electron microscope (Make: JEOL, Japan; Model: $6410 \mathrm{LV}$ ) at higher magnification to study the fracture morphology to establish the nature of the fracture.

\section{RESULTS}

\subsection{Tensile and Impact Properties}

The transverse tensile properties such as yield strength, tensile strength and percentage of elongation of SMAW, GMAW and GTAW joints were evaluated. In each condition, three specimens were tested, and the average of three results is presented in Table 3. Of the three welded joints, the joints fabricated by GTAW exhibited higher strength values, and the enhancement in strength value is approximately $32 \%$ compared to GMAW joints and $20 \%$ compared to SMAW joints. Charpy impact toughness values of all the joints were evaluated and they are presented in Table 3. The impact toughness of unwelded base metal is $22 \mathrm{~J}$. Of the three welded joints, the joints fabricated by GTAW process exhibited higher impact toughness values, and the enhancement in toughness value is approximately $11 \%$ compared to SMAW joints and $22 \%$ compared to GMAW joints.

\subsection{Hardness and Microstructure}

Vickers micro hardness measured at the weld region of the joints is presented in Table 3. The hardness of the SMAW and GMAW joints in the fusion zone region is $198 \mathrm{VHN}$ and $220 \mathrm{VHN}$ respectively. However, the hardness of the GTAW joints in the fusion zone region is $234 \mathrm{VHN}$, which is relatively higher compared to SMAW and GMAW joints.

Table 3

Transverse tensile, hardness and impact properties of base metal and welded joints

\begin{tabular}{cccccc}
\hline Joint & $\begin{array}{c}\text { Yield } \\
\text { Strength } \\
(\mathbf{M P a})\end{array}$ & $\begin{array}{c}\text { Tensile } \\
\text { Strength } \\
(\mathbf{M P a})\end{array}$ & $\begin{array}{c}\text { Wlongation } \\
(\%)\end{array}$ & $\begin{array}{c}\text { WM region } \\
\text { Hardness (Hv) }\end{array}$ & $\begin{array}{c}\text { Impact } \\
\text { Toughness (J) }\end{array}$ \\
\hline BM & 359 & 480 & 12 & 330 & 22 \\
SMAW & 205 & 288 & 10.55 & 275 & 24 \\
GTAW & 185 & 242 & 8.65 & 261 & 27 \\
GMAW & 290 & 360 & 11.25 & 247 & 21 \\
\hline
\end{tabular}


The optical micrographs of weld metal region of joints are displayed in Figure 2. The joints fabricated by SMAW, GMAW and GTAW processes primarily contain solidified dendritic structure of austenite.

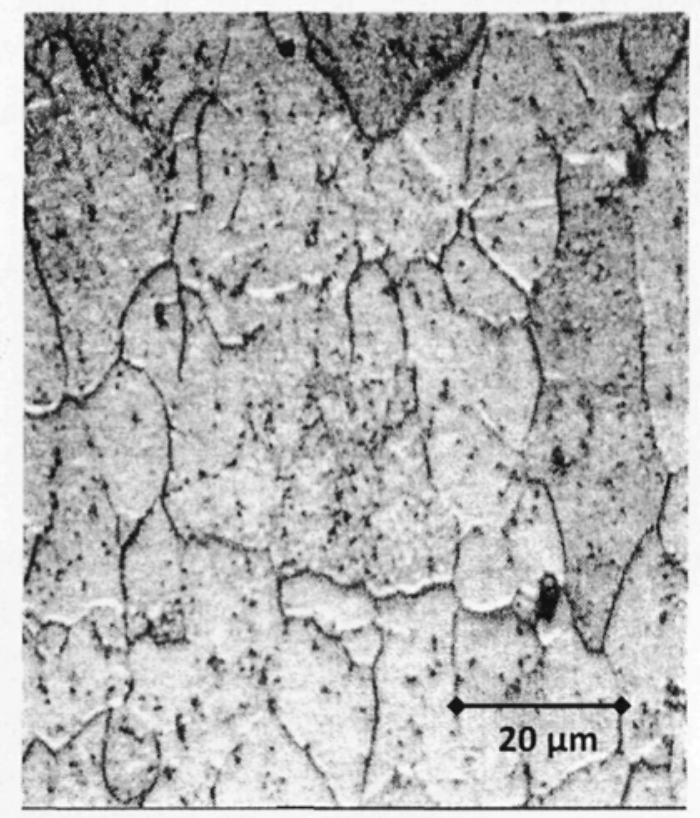

a) Base metal

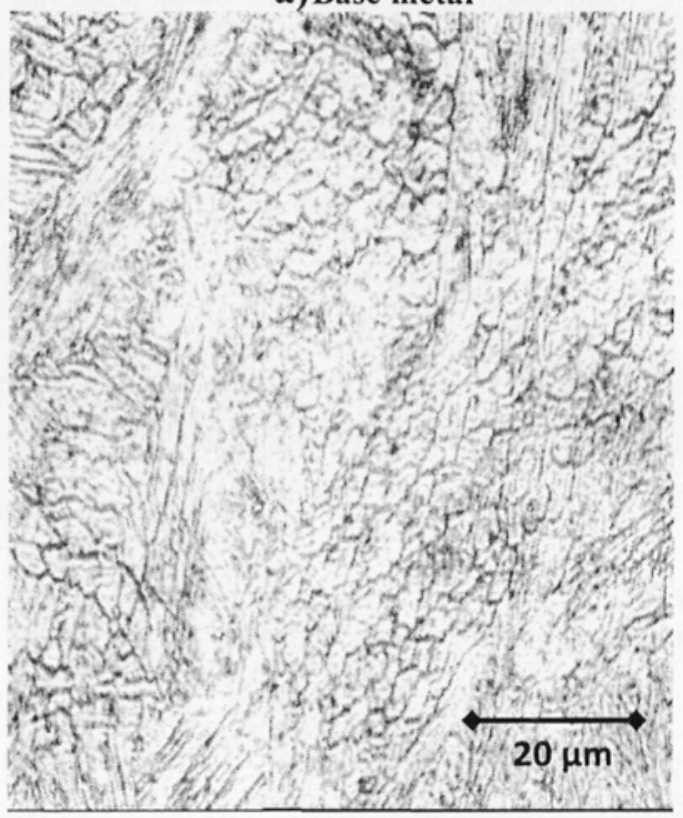

c) GTAW

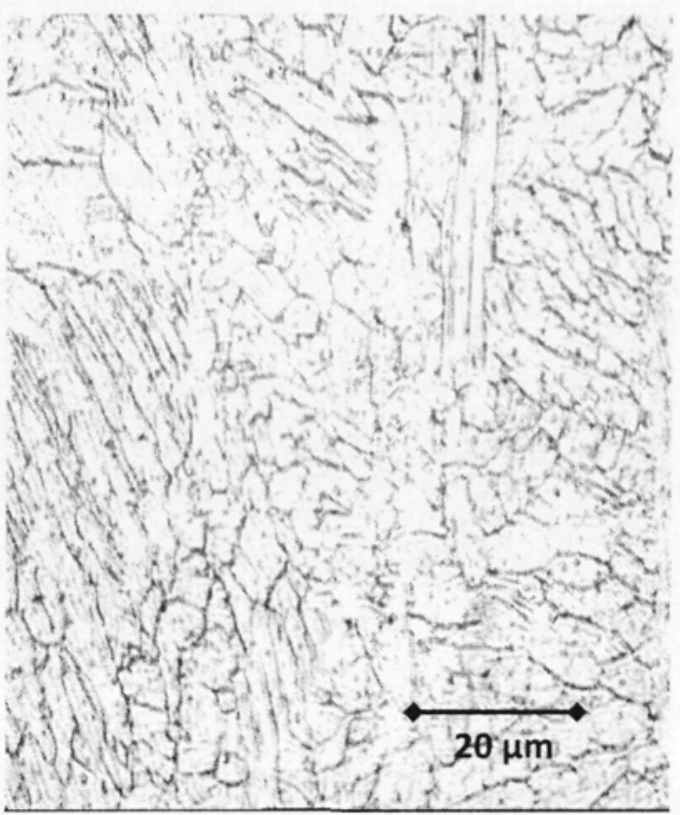

b) SMAW

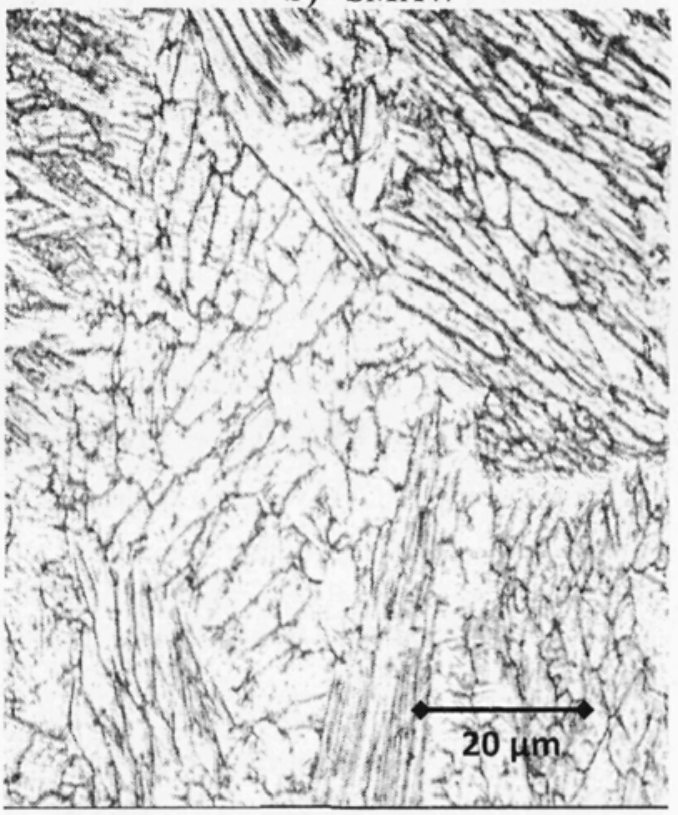

d) GMAW

Fig. 2: Optical micrographs of base metal and weld metal region 


\subsection{Fatigue Properties}

The fatigue crack growth experiments were conducted at five different stress levels $(\Delta \sigma)$ of $75,100,125$, 150 and $175 \mathrm{MPa}$ and under constant amplitude loading conditions $(\mathrm{R}=0)$. The measured variation in crack length (2a) and the corresponding number of cycles $(N)$ endured under the action of particular applied stress range are plotted as shown in Figure 3 for all the joints. The fracture mechanics based Paris Power equation (1), given below, was used to analyse the experimental results.

$$
d a / d N=C(\Delta K)^{m}
$$

Where da/dN, crack growth rate; $\Delta K$, stress intensity factor (SIF) range; 'C'and ' $m$ ' are constants. The SIF value was calculated for different values of growing fatigue crack length ' $2 a$ ' using the following expression (2)

$$
\Delta K=\phi(\Delta \sigma) \sqrt{\pi a}
$$

However, the geometry factor for the CCT specimen was calculated using the expression given below (3)

$$
\phi=F(\alpha)=\sec \left\{\frac{\alpha}{2}\right\}
$$

The crack growth rate, $\mathrm{da} / \mathrm{dN}$ for the propagation stage was calculated for the steady state growth regime, at different intervals of crack length increment, against the associated number of cycles to propagation. The relationship between SIF range and the corresponding crack growth rate in terms of best fit lines is shown in Figure 4 for all the joints. The data points plotted in the graph mostly correspond to the second stage of Paris sigmoidal relationship (10-6 to $10-3 \mathrm{~mm} / \mathrm{cycle}$ ). The exponent ' $\mathrm{m}$ ', which is the slope of the line on $\log -\log$ plot and the intercept ' $\mathrm{C}$ ' of the line, were evaluated and they are presented in Table 4

When the crack growth rate attains $10-6 \mathrm{~mm} /$ cycle, the corresponding $\Delta \mathrm{K}$ value is taken as threshold SIF range $(\Delta \mathrm{K}$ th). Similarly, when the crack growth rate attains $10-3 \mathrm{~mm} /$ cycle, the corresponding $\Delta \mathrm{K}$ value is taken as critical SIF range $(\Delta \mathrm{Kcr})$. The values of $\Delta \mathrm{Kcr}$ and $\Delta \mathrm{Kth}$ for all joints have been evaluated and are presented in Table 4. Normally, in the case of steels, the threshold value is obtained for a crack growth rate of $10-8 \mathrm{~mm} /$ cycle. Due to the specimen configuration and loading conditions, crack propagation rates in the region of $108 \mathrm{~mm} / \mathrm{cycle}$ could not be obtained. The fatigue crack growth (fracture mechanics) parameters of all the joints are compared in Table 4. 

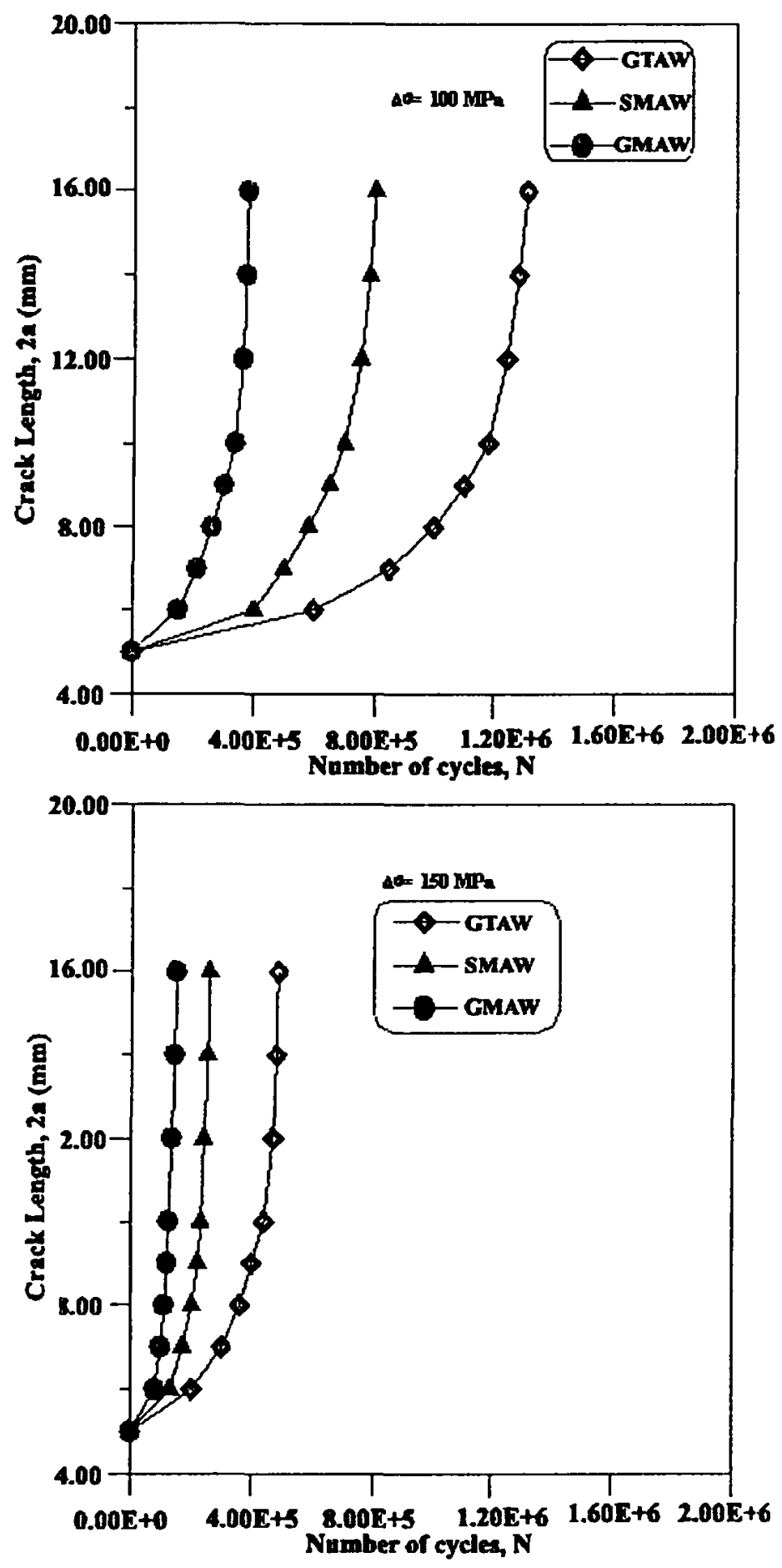

Fig. 3: Fatigue crack growth behaviour 


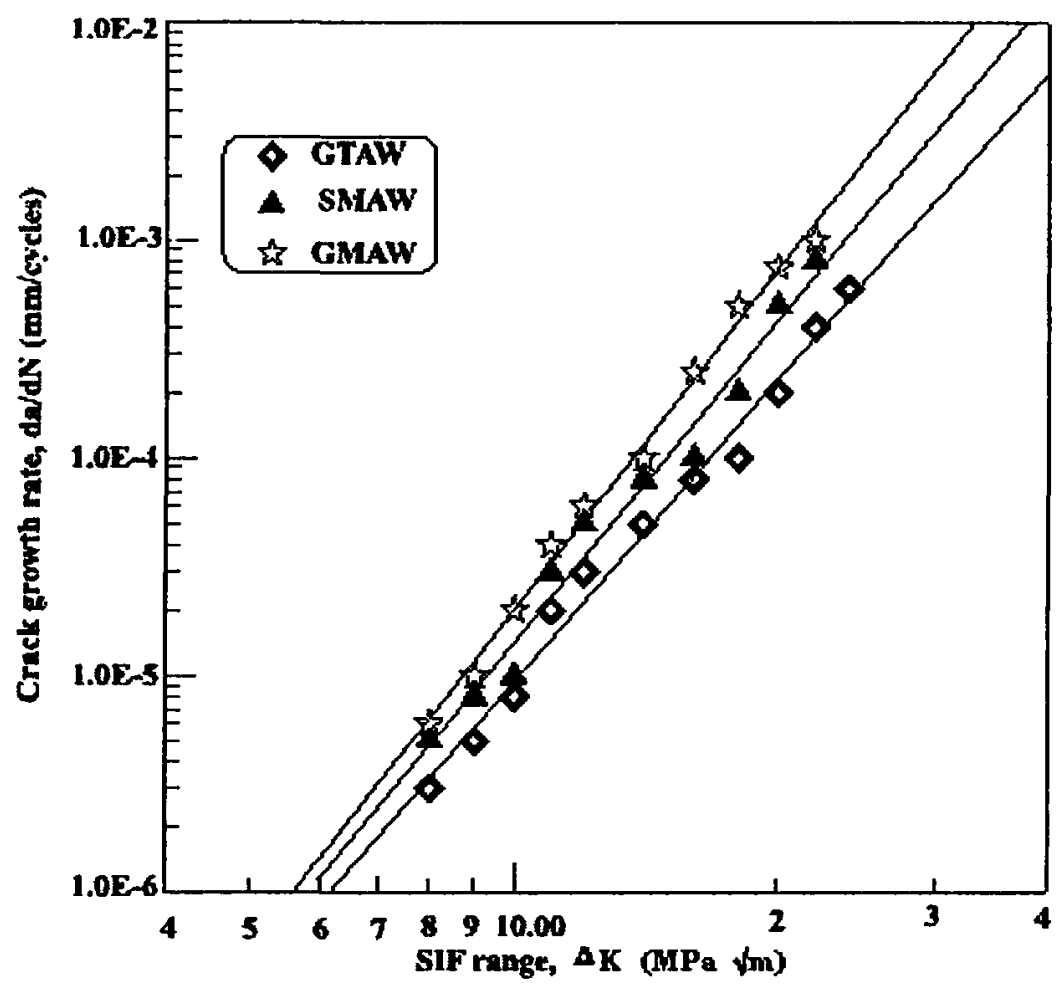

Fig. 4: Relationship between FCGR and SIF range

Table 4

Fatigue Parameters of Welded Joints

\begin{tabular}{cccccccc}
\hline Joints & $\mathrm{m}$ & $\mathrm{C}$ & $\mathrm{n}$ & $\mathrm{A}$ & $\begin{array}{c}\Delta \mathrm{Kth} \\
\left(\mathrm{MPa} V_{\mathrm{m}}\right)\end{array}$ & $\begin{array}{c}\Delta \mathrm{Kcr} \\
\left(\mathrm{MPa}{ }_{\mathrm{m}}\right)\end{array}$ & $\begin{array}{c}\Delta \sigma \mathrm{e} \\
(\mathrm{MPa})\end{array}$ \\
\hline SMAW & 4.92 & $1.69 \times 10-10$ & 2.67 & $1.4 \times 1011$ & 5.5 & 20 & 65 \\
GTAW & 4.63 & $2.18 \times 10-10$ & 2.42 & $1.1 \times 1011$ & 6.3 & 30 & 75 \\
GMAW & 5.45 & $1.56 \times 10-10$ & 2.12 & $8.7 \times 1010$ & 5.0 & 18 & 50 \\
\hline
\end{tabular}

It is also advantageous to determine the standard S-N curve for the test conditions, which will indicate the trend and also be useful for design purposes. Figure 5 shows the relationship between stress range and the number of cycles to failure on a log-log plot for all the joints. The stress corresponding to $2 \times 106$ cycles is taken as an indication of the endurance limit 9 , and these values were determined for all the joint combinations and are presented in Table 4.

The fatigue crack initiation (FCI) life, $\mathrm{Ni}$, is evaluated experimentally using the crack "initiation criteria". The initiation criterion is based on the assumption that the number of cycles required for a crack to grow an excess of $0.5 \mathrm{~mm}$ length from its original (initial) length, at the earlier crack growth stage under particular 
stress level. This is because at this stage, the crack is expected to attain more regular and stable front shape. Similar criteria were adopted by other investigators also 10,11. Figure 5 shows the relationship exists between applied stress range $(\mathrm{S})$ and the crack initiation life $(\mathrm{Ni})$ for all the joints. Each endurance line can be represented by a Basquin type equation, in general form, as expressed below:

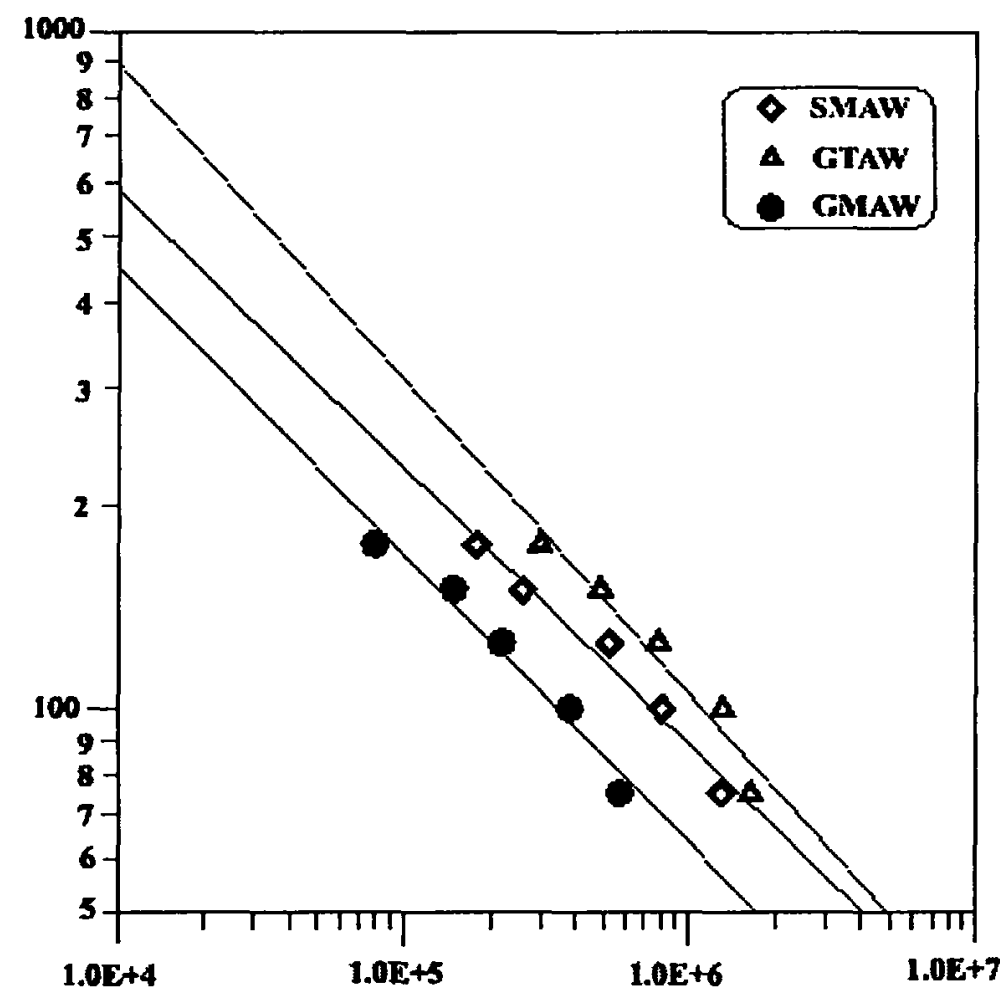

Fig. 5: S-N behaviour

$$
N_{1}=A(\Delta \sigma)^{-\prime \prime}
$$

Where ' $A$ ' and ' $n$ ' are constants (' $n$ ' is slope of the line and ' $A$ ' is intercept of the line) and their values were evaluated and presented in Table 4

\subsection{Fracture surface}

The fatigue fracture surface appearance corresponding to crack initiation, crack propagation and the final failure regions of the joints (100 MPa alone), as observed under the Scanning Electron Microscope (SEM) is displayed in Figure 6. The fatigue crack initiation region (FCI) is corresponding to $1 \mathrm{~mm}$ from the tip of the machined notch; fatigue crack propagation (FCP) region is referred to 1 to $6 \mathrm{~mm}$; final failure (FF) region is 
referred to $6 \mathrm{~mm}$ away from the crack initiation region. In all the $\mathrm{FCl}$ regions, the crack initiations sites are clearly visible and it can be observed from the fractographs that the fatigue cracks were initiated from multiple crack initiation sites.

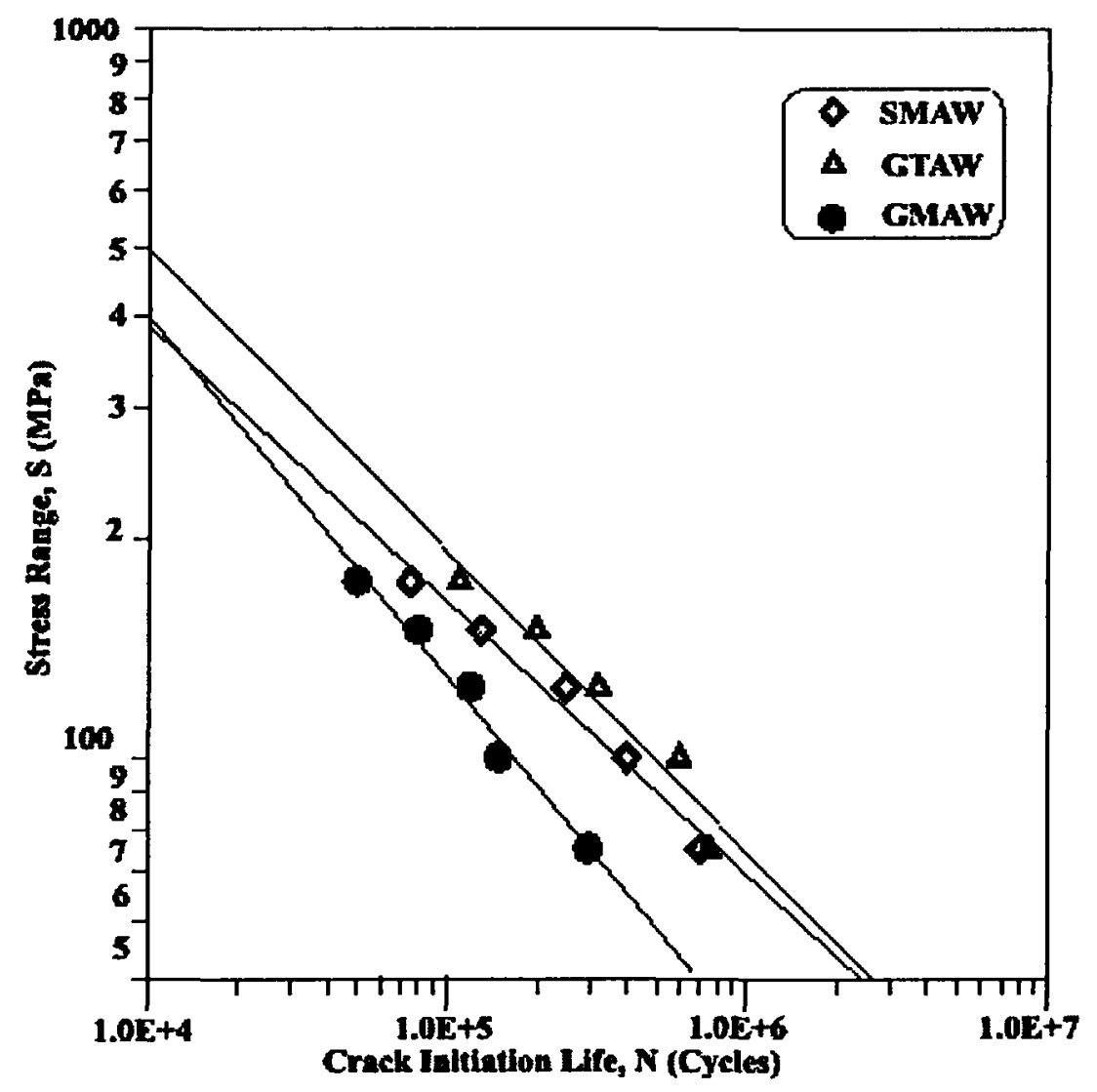

Fig. 6: Fatigue crack initiation behaviour

Invariably in FCP regions (where steady state crack growth occurs) of all the joints, the micro-level striations were observed and the spacing between the micro-level striations varies in each joints. From the fractographs of final failure region, it is observed that the tear dimples are elongated along the loading direction and this is mainly because of the limit load condition at the time of final fracture. Even though unstable crack growth occurs in the final failure region, the final fracture is still in the ductile mode and it is evident from the presence of dimples. But the shape and size of the dimples are different in all the joints and it is influenced by the grain size of the fusion zone region. 


\subsection{Residual Stresses}

Table 5 shows the measured residual stress values (measured by RIGAKU - X Ray diffractometer). In the $\mathrm{CC} \Gamma$ specimens, the measured residual stress values are in compressive and this is mainly due to the reason that after welding the joints were sliced, machined and ground to obtain the required dimensions of CCT specimen. Because of the above mentioned machining operations. the original tensile residual stresses caused by welding operation are relieved and subsequently, compressive stress fields are generated due to the compressive load acted on the specimen during grinding operation.

Table 5

Measure residual stresses

\begin{tabular}{ccc} 
& \multicolumn{2}{c}{ Magnitude of residual stress in the weld metal (WMM) region, MPa } \\
\cline { 2 - 3 } Joint Type & Joints & CCT Specimen \\
\hline SMAW & +165 & -35 \\
GTAW & +130 & -75 \\
GMAW & +180 & -15 \\
\hline
\end{tabular}

\section{DISCUSSION}

The fatigue crack initiation behaviour, fatigue crack growth behaviour and fatigue life of the FSS Joints are influenced by the welding processes. Of the three joints, GTAW joints are offering higher fatigue crack growth resistance than SMAW and GMAW welded joints. In the CCT specimen, the notch is machined in the fusion zone region of the joints by wire cut EDM (electric discharge Inachining) process to evaluate the crack growth behaviour of the welded joints under fatigue loading. 1 he fatigue crack initiates from the tip of the machined notch and it grows in the weld metal region until final failure takes place and hence the tensile and impact properties of weld metals, hardness and microstructure of weld metals and magnitude of residual stress in weld metal region will have greater influence on fatigue performance of the joints.

The weld region microstructure depends upon weld thermal cy'cles or in other words by heat input supplied by the welding process involved. GTAW process produced solidified dendritic structure of austenitic grains with smaller dendritic arm spacing compared to GMAW and SMAW processes (Figure 2). This microstructure generally offers improved resistance to indentation and deformation which in turn offer more resistance to fatigue crack propagation and this may be the reason for improved fatigue performance of GTAW welded joints compared to GMAW welded joints. The heat input supplied by the GMAW process is relatively higher than SMAW and GTAW processes. The heat input involved in the GГAW process is comparatively lower than SMAW and GMAW processes (Table 1). These variations in heat input of the 
welding processes influence the weld thermal cycle and subsequently causes variations in microstructural features and mechanical properties.

The tensile properties (yield strength, tensile strength and elongation) of GTAW joints are superior as compared to their counterparts (see Table 3). Higher yield strength and tensile strength of the GTAW joint is greatly used to enhance the endurance limit of the joints and hence the fatigue crack initiation is delayed. Larger elongation (higher ductility) and higher toughness (impact strength) of the GTAW joints also impart greater resistance to fatigue crack propagation and hence fatigue failure is delayed. The combined effect of higher yield strength, higher ductility and higher toughness of the GTAW joint offers enhanced resistance to crack initiation and crack propagation and hence the fatigue performance of the joints is superior as compared to their counterparts.

In fusion welding, during heating cycle, the expansion of weld metal is resisted by the surrounding base metal but during cooling cycle, the contraction of weld metal is also resisted by the surrounding base metal. Due to the restraint offered by the base metal during expansion and contraction of weld metal, a tensile residual stress field is generated in the weld region 12. In fusion welding processes, the generation of residual stress field in the weldment mainly depends on the welding parameters such as arc voltage, welding current and welding speed and subsequently heat input of the welding process. If the heat input of welding process is higher, then the magnitude of tensile residual field in the weld region will be greater.

Of the three welding processes used in this investigation to fabricate the AISI 409M grade FSS, the heat input involved in GMAW process is relatively higher compared to SMAW and GTAW processes. Hence the magnitude of tensile residual stress in GMA welded joints is higher compared to other joints and this is also evident from the measured residual stress values presented in Table 5. The GTAW welded joint contains lower magnitude of tensile residual stress field in the weld region as compared to GMAW and SMAW welded joints.

Residual stresses are usually relieved during fatigue cycling due to high strains/stress concentrations around the crack front. However, in this investigation the applied stress range is $75-180 \mathrm{MPa}$ which is much lower than the yield strength of the weld metals as well as base metal. Hence, the stresses and stress concentrations along the crack front were not high and as a result they were not relieved during fatigue cycling. Moreover, the residual measurement was carried out mainly to understand the effect of heat input of welding processes and also to know the initial condition (stress state) of the test specimens.

Even though the compressive load acts on the specimen during grinding is uniform, the resultant residual stress values are different and this may be due to the differences existed in the initial (as welded condition) tensile residual stress values. From the measured residual stress values (Table 5), it can be inferred that the magnitude of resultant compressive stress field in gas tungsten arc welded (GTAW) CCT specimen is relatively higher than SMA and GMA welded specimens. This may be the reason for slower fatigue crack growth rate observed in GTAW joints since compressive residual stresses usually retard the rate of fatigue crack growth 13, 14. 


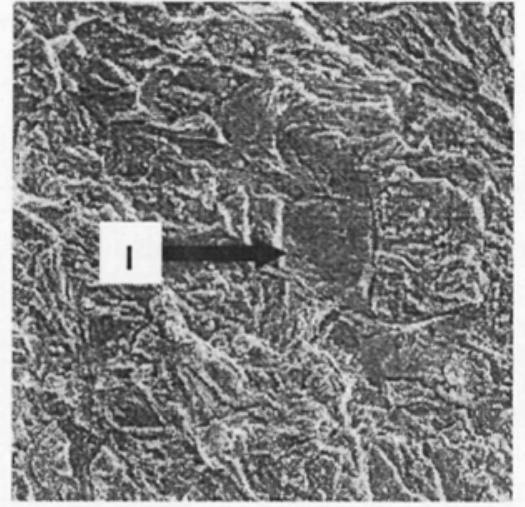

a) SMAW - FCI Region

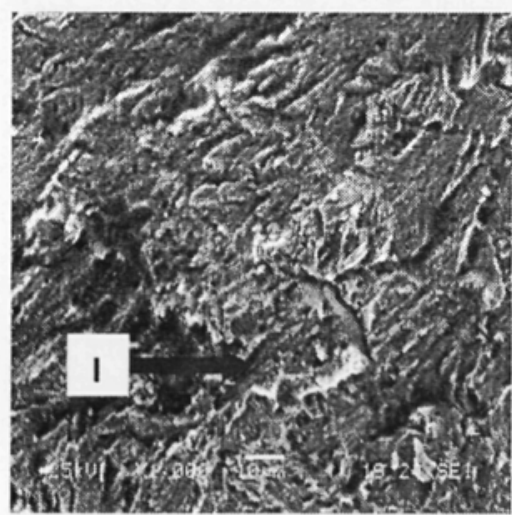

d) GTAW - FCI Region

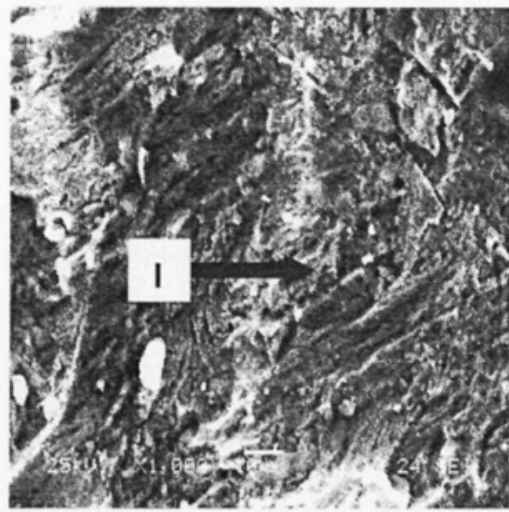

g) GMAW - FCI Region

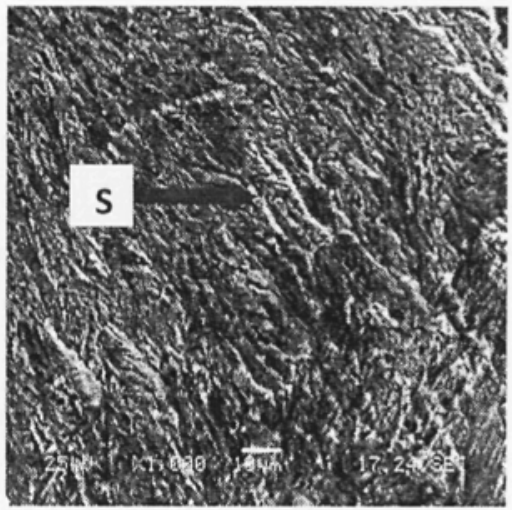

b) SMAW - FCP Region

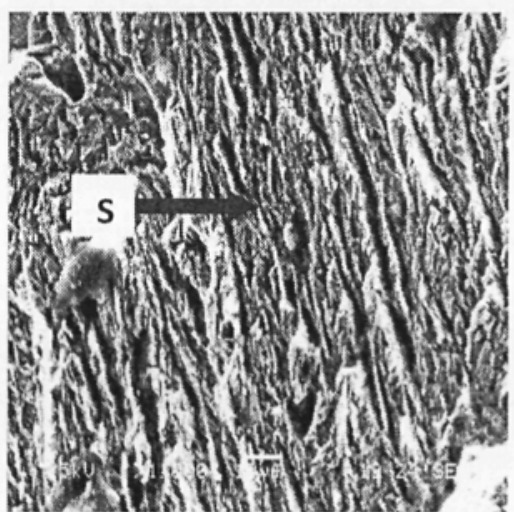

e) GTAW - FCP Region

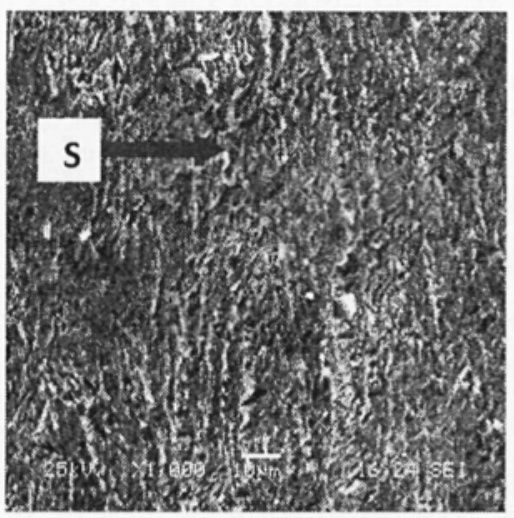

h) GMAW - FCP Region

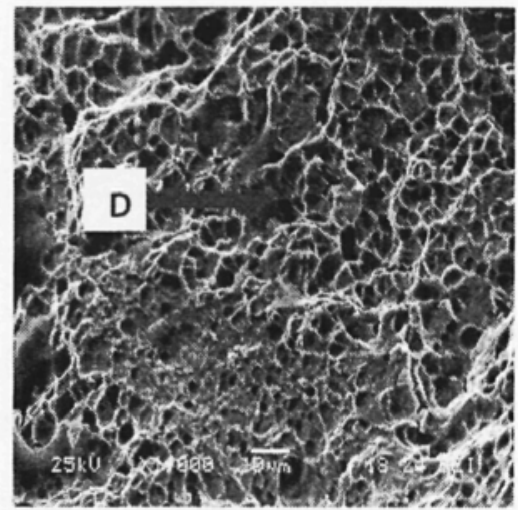

c) SMAW-FF Region

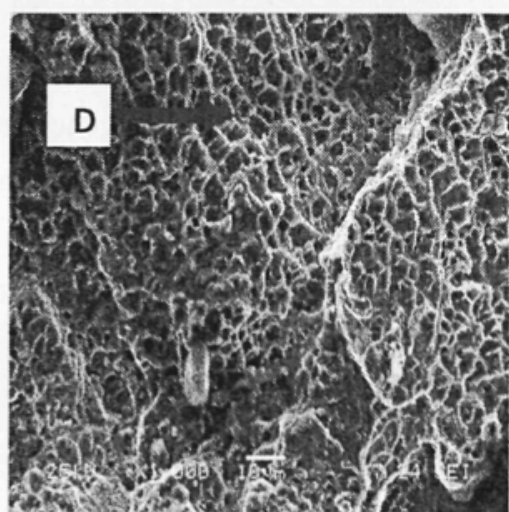

f) GTAW-FF Region

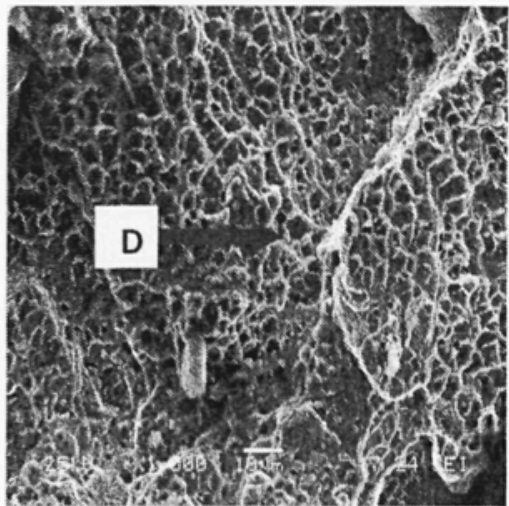

i) GMAW-FF Region

Fig. 7: SEM fractographs of welded joints

(FCI: Fatigue Crack Initiation; FCP: Fatiguc Crack Propagationl;

FI: final failure I- Initiation; S-Straition; $\dot{D}$-Dimples) 


\section{CONCLUSIONS}

From this investigation, the following conclusions are derived:

1. The fatigue performances of GTAW joints are superior compared to the GMAW and SMAW joints.

2. Lower heat input, finer fusion zone grain diameter, higher fusion zone hardness may be the reasons for superior tensile and impact properties of GTAW joints compared to GMAW and SMAW processes.

3. The superior mechanical properties (higher yield strength and toughness), preferred microstructures in the fusion zone region (closely spaced dendrites) and favourable residual stress field in the fusion zone region (large magnitude of compressive stress) are the reasons for better fatigue performance of GTAW joints.

\section{ACKNOWLEDGEMENTS}

The authors are grateful to the Department of Manufacturing Engineering, Annamalai University, Annamalainagar, Tamil Nadu, India for extending the facilities of Metal Joining Laboratory and Materials Testing Laboratory to carryout this investigation. The authors are very grateful to Dr.G.Madhusudhan Reddy, Scientist-F, Defence Metallurgical Research Laboratory (DMRL), Hyderabad for his valuable suggestions, guidance and discussion.

\section{REFERENCES}

1. Sathiya, P., Aravindan, S. and Noorul,Haq, A. Effect of friction welding parameters on mechanical and metallurgical properties of ferritic stainless steel. Int J Adv Manuf Technol 2007;31; 1076-1082.

2. Pickering, F.B., Physical metallurgy of stainless steel developments. Int. Met. Rev. 1976; 21; 227-268.

3. Villafuerte. J.C. and Kerr, H.W. Grain Structures in gas tungsten arc welds of austenitic stainless steels with ferrite primary phase. Metallurgical Transactions A, 1990; 21 A; 979-986.

4. Villafuerte, J.C., Kerr, H.W. and David, S.A. Mechanisms of equiaxed grain formation in ferritic stainless steel gas tungsten arc welds. Material Science and Engineering A, 1995; 194; 187 - 191.

5. Mohandas, T.,Madhusudhan, Reddy, G. and Mohammad Naveed. A comparative evaluation of gas tungsten and shielded metal arc welds of a ferritic stainless steel. Journal of Materials Processing Technology 1999; 94; $133-140$.

6. Meyers, A.M. and du Toit, M. Interstitial diffusion of carbon and nitrogen into heat affected zones of 11 $12 \%$ chromium steel welds. Welding Research Supplement, 2001;275-s - 280-s. 
7. Cleiton C. Silva, Jesualdo Farias P, Helio Miranda C, Rodrigo Guimaraes F, John Menezes WA, Moises Neto AM. Microstructural characterization of the HAZ in AISI $44+$ ferritic stainless steel welds. Materials Characterization 2008; 59(1); 528.

8. Balasubrmanian ,V., Shanmugam, K. and Lakshminarayanan, A.K. Effect of autogeneous welding processes on fatigue crack growth behaviour of ferritic stainless steel joints. Iron and Steel Institute of Japan, 2008; 48 (4); 494.

9. Ravi, S., Balasubramanian, V. and Nemat Nasser S. Effect of notch location on fatigue crack growth behavior of strength-mismatched high-strength low-alloy steel weldments Journal of Materials Engineering and Performance 2004; 13 ; 758-765.

10. Testin, R.A., Young, J.Y., Jr.Lawrence F.V. and Rice, R.C.: Welding Journal 1987; 56; 259s

11. Guha, B., A new fracture mechanics method to predict the fatigue life of welded cruciform joints. Engineering Fracture Mechanics, 1995; 52; 215.

12. S.J.Maddox, Fatigue strength of welded structures, Cambridge University Press, London, 1991.

13. R.S.Parmar, Welding Processes and Technology, Khanna Publishers, New Delhi. 2003.

14. D.Radaj, Design and analysis of Fatigue Resistant Welded Structures, Abington Publishing, Cambridge, England, 1990. 